\title{
Correction to: Impact of IT capabilities on supply chain capabilities and organizational agility: a dynamic capability view
}

\author{
Muhammad Irfan ${ }^{1,2} \cdot$ Mingzheng Wang ${ }^{3} \cdot$ Naeem Akhtar ${ }^{4}$ \\ Published online: 12 October 2020 \\ (C) Springer Science+Business Media, LLC, part of Springer Nature 2020 \\ Correction to: Operations Management Research (2019) 12:113-128 \\ https://doi.org/10.1007/s12063-019-00142-y
}

The original version of this article unfortunately contained a mistake. One of the affiliations of the first author was missing. The correct information is given below.

Publisher's note Springer Nature remains neutral with regard to jurisdictional claims in published maps and institutional affiliations.

The online version of the original article can be found at https://doi.org/ 10.1007/s12063-019-00142-y

\section{Mingzheng Wang}

wangmzh@zju.edu.cn

Muhammad Irfan

irfanvoe@mail.dlut.edu.cn; irfan.ch@ue.edu.pk

Naeem Akhtar

naeem.uibe@hotmail.com

1 Faculty of Management and Economics, Dalian University of Technology, Dalian 116024, People's Republic of China

2 Department of Economics and Business Administration, University of Education, Lahore 54000, Pakistan

3 School of Management, Zhejiang University, Hangzhou 310058, People's Republic of China

4 Department of Marketing, School of Business, University of International Business and Economics, Beijing 100029, People's Republic of China 